\title{
Umbilical Hernia in Cross Holstein Friesian Calf and its Surgical Management: A Case Report
}

\author{
Haben Fesseha, MVSc, DVM* \\ Department of Veterinary Surgery and Diagnostic Imaging, School of Veterinary Medicine, Wolaita Sodo University, P. O. Box I38, Wolaita Sodo, Ethiopia \\ *Corresponding author \\ Haben Fesseha, MVSc, DVM \\ Assistant Professor, Department of Veterinary Surgery and Diagnostic Imaging, School of Veterinary Medicine, Wolaita Sodo University, P. O. Box I38, Wolaita Sodo, \\ Ethiopia;Tel. +25I9I0737790; ORCID: 0000-000I-65 I6-3036; E-mail: tsseyon.h@gmail.com
}

\section{Article information}

Received: June 28 ${ }^{\text {th }}, 2020$; Revised: August $5^{\text {th }}, 2020$; Accepted: August 19th 2020 ; Published: August $31^{\text {st }}, 2020$

\section{Cite this article}

Fesseha H. Umbilical hernia in cross Holstein Friesian calf and its surgical management:A case report. Vet Med Open J. 2020; 5(2): 39-42. doi: 10.17/40/VMOJ-5-I47

\section{ABSTRACT}

A three-months-old Holstein Friesian crossbred calf weighing $56 \mathrm{~kg}$ was presented to Veterinary Teaching Hospital, Mekelle University, Ethiopia with a history of swelling at the umbilical region from birth since last few months. Clinical examination revealed umbilical hernia with a hernial ring of 3 fingers breadth. The case was handled surgically by means of herniorrhaphy using overlapping mattress suture techniques and synthetic absorbable polyglycolic acid. The calf has unevenly recovered on the $20^{\text {th }}$-day post-operation. The present case report discusses the successful management of umbilical hernia in the calf.

\section{Keywords}

Calf; Herniorrhaphy; Overlapping mattress suture; Umbilical hernia.

\section{INTRODUCTION}

$\mathrm{A}^{\mathrm{h}}$ hernia is the protrusion or displacement of an organ, part of an organ, or tissue outside the abdominal cavity through an abnormal opening in the abdominal wall which can be noted from the outside of an animal's body and can be detected with an external examination. There are different types of hernia in small and large animals that are classified according to their anatomical locations into umbilical, inguinal, scrotal, femoral, perineal, and ventral (or abdominal) hernias. ${ }^{1,2}$

Umbilical hernia is the the most common form of congenital hernia in calves. However, many umbilical hernias are secondary to umbilical sepsis. Umbilical hernia can be divided into 3 categories including uncomplicated umbilical hernia, umbilical hernia with subcutaneous infections (abscess), and umbilical hernia with umbilical remnant infection. The most common cause is due to failure of normal development and closure of umbilicus, infection at the site of the umbilicus, manual breakage of the umbilicus, clamping, or ligation of the umbilical cord and potentially excessive straining., 3

An umbilical hernia is caused as a result of the failure of the abdominal musculature to close properly around the umbilical structures, however, the mechanism or reasons for failure to closure are not known. Besides, heritable factors, inflammation and sepsis of the umbilicus, post-calving infection of umbilical infection, breakage of the umbilicus during manual traction of the fetus, external trauma to the umbilicus, excessive straining, cloned calves (less collagen in the ventral abdominal wall), hypoplasia of the abdominal musculature, and multiple births (twins, triplets, etc) are considered as the cause and predisposing factor for umbilical hernia. ${ }^{5,6}$

According to previous reports, an umbilical hernia occurs more frequently in Holstein Friesian calves. However, it can occur in any breed of cattle. Calves of 5-7-weeks of age are among the most affected age groups with umbilical hernia and it is reported 4 to $15 \%$ of the calves. Females are much more frequently affected than males. ${ }^{7,8}$ Small umbilical hernias have an internal hernial ring size of less than $2 \mathrm{~cm}$ diameter. Besides, there less chance of strangulation since the ring size is too small for abdominal contents to pass except for omentum. On the other hand, if the internal ring size is more than $2 \mathrm{~cm}$ diameter, there should be a potential site of abomasal and intestinal incarceration., ${ }^{2,9}$

An umbilical hernia can be symptomatic or asymptomatic upon their clinical presentation and usually seen shortly after birth. Besides, it is usually painless if it is non-strangulated and non-infected hernias and omentum, small intestine, or abomasum are the 
most common contents that appear in most cases of umbilical hernia. The size and shape of the hernial ring vary from ring diameter of less than $2 \mathrm{~cm}, 2-5 \mathrm{~cm}$, greater than $5 \mathrm{~cm}$ ring diameter. Moreover, the nature of the umbilical ring determines the degree of fibrosis and the possibility of suture retention. ${ }^{4,10}$

The condition can be easily diagnosed by observing clinical signs, through external digital palpation and ultrasonography (especially for non-reducible hernias to identify contents of the hernial sac and differentiate from umbilical abscessation). It can be managed using various medical and surgical methods. The prognosis depends on the type and condition of hernia. Besides, early diagnosis and treatment of the condition improve the outcome of the umbilical hernia. ${ }^{11,12}$ The umbilical hernia should be differentiated from disease conditions like omphalitis, omphaloarteritis, omphaloarteritis or phlebitis, omphalophelbitis, acquired hernia, rupture of abdominal wall, umbilical abscess and urachal cysts or rupture. Since such cases are mostly associated with a hereditary element, careful consideration should be given when if the animals is goning to be used for further breeding. ${ }^{1,6,13}$

Most hernias enlarge over time and, if not repaired surgically, they may cause pain, anorexia, weight loss, or it may cause dystocia when a gravid horn is found in the hernial sac. Incarceration and strangulation of the bowel are the most dangerous lifethreatening sequela of herniation. ${ }^{4,14}$ Reports on hernias in small ruminants are very rare. ${ }^{3,15-17}$ Thus, radical surgery is the best option for the majority of symptomatic or asymptomatic umbilical hernias and is one of the most common surgical procedures performed. ${ }^{18,19}$ Despite its commonness, it is generally ignored by the rural farmers unless it results in some serious forms and affecting the productivity and reproductivity of the animals. The present study describes the successful management of an umbilical hernia in a calf.

\section{CASE PRESENTATION}

\section{History and Clinical Observations}

A three-months-old Holstein Friesian crossbred calf weighing 56 $\mathrm{kg}$ was presented to the Veterinary Teaching Hospital, College of Veterinary Science, Mekele University, with a history of swelling at the umbilical region from birth but increasing in size since last few months. The clinical examination revealed reducible swelling that dangles around the umbilicus (Figure 1A). The size of the hernial ring was three fingers in breadth. The clinical parameters viz. rectal temperature, heart rate, and respiratory rate were within normal range with good body condition. Based on clinical examination, the case was diagnosed as umbilical hernia and was corrected by herniorrhaphy (overlapping mattress sutures) using synthetic sterile absorbable polyglycolic acid.

\section{Pre-operative Preparations and Anesthesia}

Food was withheld for 24-hours and water for 12-hours prior to surgery. The calf was restrained and sedated with an intramuscular administration of Ana-Sed ${ }^{\circledR}$ (Xylazine hydrochloride, Heartland Vet Supply Ltd at a dose rate of $1.1 \mathrm{mg} / \mathrm{kg}$ body weight) as well as the ring block anaesthesia was achieved by local anaesthetic two percent lidocaine (Lidocaine hydrochloride $2 \%$, Jeil pharm. Co. Ltd., Korea) with the dose rate $1 \mathrm{ml} / \mathrm{cm}$ area to desensitize the abdominal muscle and alleviate pain during surgical procedure. After proper sedation, the calf was positioned in dorsal recumbency. Then, the surgical site (umbilical area) was aseptically prepared by clipping, shaving, scrubbing, washing with water, and Salvon ${ }^{\circledR}$ (Cetrimide $3 \%$ and Chlorhexidine gluconate $0.5 \%$ solution).

\section{Surgical Correction and Treatment}

Following proper physical and chemical restraining and aseptic preparation of the surgical site, the calf was kept on the appropriate direction for the next surgical procedure. A gently and sufficient longitudinal incision was done in the middle of the swelling. The skin was detached from the subcutaneous tissue through blunt dissection and the incision was continued through the abdominal muscle and peritoneum. Then all muscular layers together with skin were grasped with a handheld retractor to get sufficient surgical field and expose hernial ring.

After careful dissection of skin and subcutaneous tissue, the condition of the hernial sac and the hernial ring was examined to confirm any adhesions in the abdominal organs. Upon insertion of a finger, slight adhesion of some part of the small intestine with the lower abdominal wall was found and it was gently detached and the herniated viscera (small intestine) (Figure 1B) were repositioned back in the abdominal cavity manually (Figure 1C). Then, a $1 \mathrm{~mm}$ dissection was performed eccentrically around the edge of the hernial ring to make the fresh wound that helps. to facilitate the healing process.

Herniorrhaphy was done by overlapping mattress sutures using synthetic sterile absorbable polyglycolic acid (Shandong Sinorgmed Int'l Co., Ltd, China) suture materials size no. 2 (Figure 1D). Moreover, The excess of distended skin was left because it would shrink to its original anatomic dimensions and position pos-

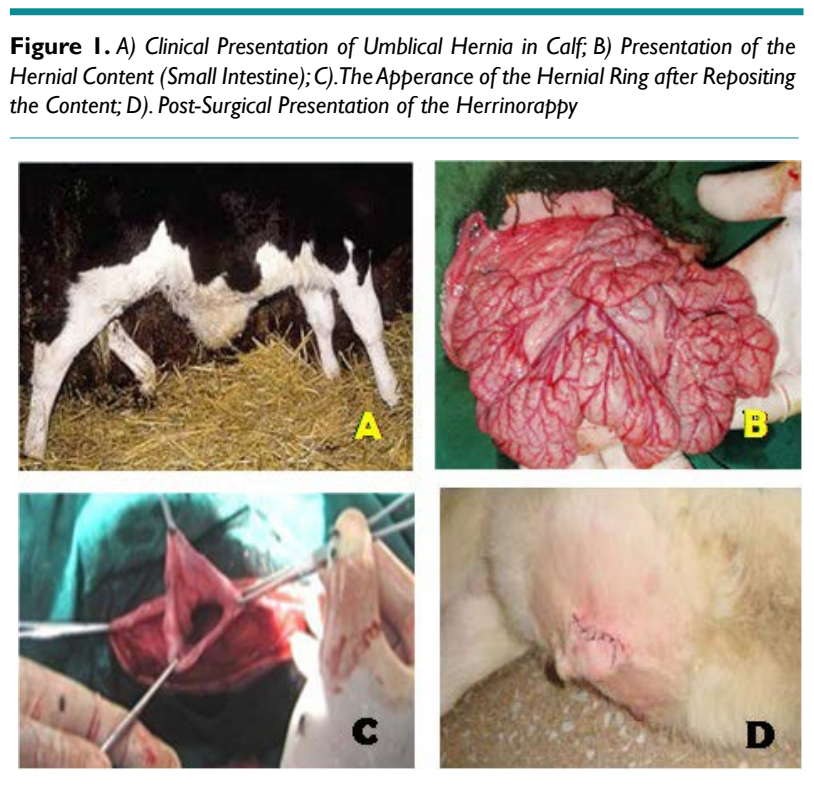


t-operatively. Then, the subcutaneous tissue and skin were closed with an interrupted horizontal mattress using silk 2-0 size and the surgical site was properly cleaned and dressed with a $1 \%$ Povidoneiodine solution and admitted home.

\section{Post-Operative Follow-up and Result}

Post-operatively, the dressing of the wound was done using a $1 \%$ Povidone-iodine solution at second- and third-days post-operation. Besides, the calf was kept on antibiotic Procaine penicillin (24 $\mathrm{mg} / \mathrm{kg}$ ) and dihydrostreptomycin sulphate $\left(30 \mathrm{mg} / \mathrm{kg}\right.$ ) (Pen-Strep ${ }^{\circledR}$ Norbrook, Great Britain) was given intramuscularly for successive five days and Meloxicam $(0.5 \mathrm{mg} / \mathrm{kg}, \mathrm{IM})$ thrice for 3 successive days. Tetracycline wound spray was also applied over the wound area. Furthermore, the owner was also advised to closely monitor the calf and advised to allow some exercise and supply with good nutrition to facilitate wound healing. The complete healing was recorded on $14^{\text {th }}$ day post-operation without reoccurrence and other complications. Finally, the skin sutures were removed on the $14^{\text {th }}$ day post-operatively.

\section{DISCUSSION}

Hernias have different congenital and acquired causes that have several deleterious effects, such as lowering the productivity and reproductivity of the affected animals. ${ }^{5}$ Umbilical hernias are quite commonly observed in young calves..$^{10}$ Similarly, in the current case report, umblical hernia is seen in three month old calf. Besides, incidence of congenital defects in cattle is $0.2-3 \%$, with $40-50 \%$ born dead and such defects are commonly visible externally. Congenital defects including umbilical hernia, reduce the value of affected calves and should be manged using surgical operation. The condition is a very common in dairy cattle especially in Holstein Friesian breeds. It may be inherited by a dominant character within complete penetrance, or be conditioned by environmental factors. $^{20}$

According to the current case report, congential umbilical hernia is presented in holestein fresian cross young calf with a three finger breadth. This is similar to the previous reports which stated that, congenital umbilical hernias is common in Holsteins calf and mostly associated with heritability. Hernias are made up of hernia sac, peritoneum, and may contain peritoneal fliud and viscera. The most common viscera involved in umbilical hernias in cattle were the abomasum with or without omentum. Hernias may be small at birth and enlarge with age and should be differentiated from umbilical sepsis. ${ }^{21}$ The umbilical opening in calf should be closed after birth in a few days. Failure of this opening to close properly results in umbilical hernia and its cause might be either congenital or acquired factors that hamper this closure, such as omphalitis or abscesses. ${ }^{3}$

Umbilical hernia can be managed using different treatment options depend on the size of the hernial ring. In case of smaller herinal rings, it can be easily manged through application of bandage, clamps, or ligatures. Herniorrhaphy is the only remedy that is commonly done under local block in calves. Besides, this should be applied in case of large hernial opening (more than 1 finger in size or if it persists for more than 3 to 4-weeks) but extensive umbilical hernia warrants hernioplasty. ${ }^{4,22}$ The goal of surgical repair was to obliterate the hernia sac and repair of the defect in abdominal wall. ${ }^{23}$ Absorbable sutures can be used in cases where the size of the hernial ring is no more than 4 fingers or if the hernia is less than 8 -months old. ${ }^{3}$ Similarly, herrinorraphy was performed under proper anesthesia (regional nerve block) to manage the current case of umbilical hernia using an absorbale suture material.

Complication may develop in congenital umbilical hernias, which can signifiantly increase the complexity and expense to repair. This could be simple (or uncomplicated) hernias that is easily reducible while in case of complicated hernias (incarcerated viscera usually without strangulation, or concurrent infection of umbilical structures) cannot be completely reduced. Uncomplicated congenital umbilical hernias that have persisted until 5-6-months of age, gradually enlarged over time, or failed to respond to conservative therapy. ${ }^{24}$ Similarly, in this case case report, slight adhesion was seen during the procedure between the hernial sac and content.

\section{CONCLUSION}

Accordingly, an umbilical hernia can be managed through herniorrhaphy using overlapping mattress suture technique and synthetic absorbable polyglycolic acid as suture material and recommended as an alternative technique.

\section{ETHICAL CONSIDERATION}

The case report was done under super vison of Mekelle University, College of Veterinary Science ethical review committee and had critically reviewed and conclude that there was no ethical misconduct. The approval of ethical committee was taken for conducting this study and followed all the animal ethics and welfare guidelines.

\section{REFERENCES |}

1. Farman RH, Al-Husseiny SH, Al-Ameer ANA. Surgical treatment of hernia in cattle: A review. Al-Qadisiyah Journal of Veterinary Medicine Sciences. 2018; 17(2): 61-68. doi: 10.29079/vol17iss2art506

2. Fossum TW. Small Animal Surgery Textbook. Amsterdam, Netherlands: Elsevier Health Sciences; 2013.

3. Al-Sobayil FA, Ahmed AF. Surgical treatment for different forms of hernias in sheep and goats. J Vet Sci. 2007; 8(2): 185-191. doi: $10.4142 /$ jvs.2007.8.2.185

4. Abdin-Bey M, Ramadan R. Retrospective study of hernias in goats. Scientific Journal of King Faisal University (Basic and Applied Sciences). 2001; 2(1): 77-88.

5. Kumar A. Veterinary Surgical Techniques. Noida, India: Vikas Pub- 
lishing House Pvt Ltd; 2001.

6. Misk N, Misk T, Semieka M. Hernias in some farm animals. Paper presented at: $25^{\text {th }}$ World Buiatrics Congress; 2008; Budapest, Hungary.

7. Baxter GM. Hernias/umbilicus. In: Fubini SL, Ducharme NM, eds. Farm Animal Surgery. Philadelphia, USA: Saunders; 2004: 477483.

8. Hassen D, Kawo H, Gondore M. A preliminary study on hernia in domestic animals in Gondar Town, North Gondar, North West Ethiopia. J Vet Sci Technol. 2017; 8: 420. doi: 10.4172/21577579.1000420

9. Hosie BD. Hernias. In: Martin WB, Aitken ID, eds. Diseases of Sheep. $3^{\text {rd }}$ ed. Oxford, UK: Blackwell Science; 2000: 74-75.

10. Kumar V, Kumar N, Gangwar A, Saxena A. Using acellular aortic matrix to repair umbilical hernias of calves. Aust Vet J. 2013; 91(6): 251-253. doi: 10.1111/avj.12058

11. Salim M, Hashim MA, Juyena N, Arafat YA, Dey RK, Bag AS, et al. Prevalence of Hernia and Evaluation of Herniorrhaphy in Calves. Int. J. Nat. Soc. Sci. 2015; 2(4): 35-43.

12. Turner AS, Mcllwraith C. Techniques in Large Animal Surgery. . Philadelphia, USA: Wiley-Blackwell; 2013.

13. Fubini SL, Ducharme N. Farm Animal Surgery. Amsterdam, Netherlands: Elsevier Health Sciences; 2016.

14. Slatter DH. Textbook of Small Animal Surgery. Volume 1. Amsterdam, Netherlands: Elsevier Health Sciences; 2003.

15. Das B, Nath B, Pallab M, Mannan A, Biswas D. Successful management of ventral abdominal hernia in goat: A case report. Int J Nat Sci. 2012; 2(2): 60-62.

16. Jettennavar P, Kalmath G, Anilkumar M. Ventral abdomina hernia in a Goat. Vet World. 2010; 3(2): 93.

17. Sagar PV, Harish D, Babu PP. Ventral hernia in an Ongole cow: A case report. Vet World. 2010; 3(2): 90-91.

18. Chavez J, Demoor A. Surgical treatment of umbilical infection in calves. Veterinary Record. 2012; 77: 771-774.

19. Haile Y, Velappa R, Asrat M. A study on the prevalence of umbilical hernia in calves in and around Gondar Town, North Gondar, North West Ethiopia. International Journal of Veterinary Sciences and Animal Husbandry. 2017; 2(2): 11-15.

20. Weaver AD, Atkinson O, Jean GS, Steiner A. Bovine Surgery and Lameness. New Jersey, USA: John Wiley \& Sons; 2018.

21. Anderson DE. Surgical diseases of the neonate. Paper presented at: Proceedings of the WBC Congress; 2004; Québec, Canada.

22. Kumar A, Mohindroo J, Sangwan V, Mahajan SK, Singh K, Anand A, et al. Ultrasonographic evaluation of massive abdominal wall swellings in cattle and buffaloes. Turk J Vet Anim Sci. 2014; 38(1): 100-103. doi: 10.3906/vet-1302-21

23. Shah Z, Ahamd S, Sarwar MS, Khan MA, Ali J. Surgical intervention of umbilical hernia in dairy cross holstein friesian calf. Meat Sciences and Veterinary Public Health. 2016; 1(1): 1-3.

24. Adam SB, Fessler JF. Umblical herniorrhaphy. In: Adams S, Fessler JF, eds. Atlas of Equine Surgery. Philadelphia, USA: WB. Saunders; 2000. 